\title{
Arranjo Produtivo Local Da Piscicultura No Castanhão: Um Meio Para Disseminação De Práticas E Conhecimentos Sobre Sustentabilidade
}

\section{Castanhão Pisciculture Cluster: A Means For Dissemination Of Practices And Knowledge About Sustainability}

\author{
Adriana Teixeira Bastos ${ }^{1}$, Cláudio César Torquato Rocha ${ }^{1}$, Fátima Regina Ney Matos² $^{2}$ \\ ${ }^{1}$ Universidade Estadual do Ceará, UECE, Brasil, ${ }^{2}$ Universidade Potiguar, UNP, Brasil e Instituto Superior Miguel \\ Torga, ISMT, Portugal. \\ Correspondência: Adriana Teixeira Bastos. Av. Paranjana, 1700, Itaperi, CEP 60.740-000, Fortaleza, CE, Brasil. \\ Telefone: +55 (85) 3301-9962. E-mail: adriana.bastos@uece.br.
}

Recebido: 13 de novembro de 2017 Aceito: 01 de outubro de 2018 Publicado: 28 de dezembro de 2018

DOI: http://dx.doi.org/10.21714/1679-18272018v16n2.p103-115

\begin{abstract}
Resumo
O objetivo deste artigo é caracterizar os elementos que compõem o APL da piscicultura do Açude Castanhão: aglomerado, estrutura de governança e apoio público, em que se admite que se realiza o processo de aprendizagem de práticas e conhecimentos sobre sustentabilidade. A abordagem metodológica adotada foi qualitativa, com o emprego da técnica de análise de narrativa. Para a coleta de dados, empregou-se a entrevista, a análise documental e a observação simples. A pesquisa evidenciou a existência de aglomeração de empresas/associações/cooperativas especializadas, funcionando de maneira relativamente organizada, baseadas em interações e mecanismos de coordenação, realizado principalmente por entes públicos como a PMJ, o DNOCS, o SEBRAE e a SEAGRI/SDA. Portanto, não se trata somente de aglomeração física de empresas mantendo encontros casuais, mas da ação de atores coordenados por entidades governamentais e não governamentais, com algumas ações de governança, que aos poucos evolui para um tipo moderado, que representam um fraco, mas persistente apoio público.
\end{abstract}

Palavras-chave: Arranjo produtivo local, Sustentabilidade, Piscicultura, Castanhão.

\begin{abstract}
The objective of this article is to characterize the elements that compose the Castanhão pisciculture cluster: agglomerate, governance structure and public support, in which it is admitted that the process of learning practices and knowledge about sustainability is realized. The methodological approach adopted was qualitative, using the technique of narrative analysis. For data collection, interviews, documentary analysis and simple observation were used. The research evidenced the existence of agglomeration of specialized companies / associations / cooperatives, functioning in a relatively organized way, based on interactions and coordination mechanisms, carried out mainly by public entities such as PMJ, DNOCS, SEBRAE and SEAGRI / SDA. Therefore, it was not only a matter of physical agglomeration of companies holding casual encounters, but rather of the actions of coordinated actors, with some governance actions, which gradually evolved into a moderate type coordinated by governmental and nongovernmental entities that represented a weak, but persistent public support.
\end{abstract}

Keywords: Cluster, Sustainability, Pisciculture, Castanhão.

Esta obra está licenciada sob uma Licença Creative Commons Attribution 3.0.

\section{Introdução}

O presente artigo é parte de uma pesquisa maior que tem como objeto de investigação o processo de aprendizagem de conhecimentos e práticas sobre sustentabilidade no arranjo produtivo local (APL) da piscicultura do açude Castanhão. O objetivo é caracterizar os elementos que compõem o APL da piscicultura do Açude Castanhão: aglomerado, estrutura de governança e apoio público, em que se admite que se realiza o processo de aprendizagem de práticas e conhecimentos sobre sustentabilidade.

$\mathrm{O}$ contexto que permeia a problemática aqui estudada ressalta o fato de que os conceitos de sustentabilidade e 
desenvolvimento sustentável (DS), com o final do século XX, tornaram-se não só uma base teórica relevante, mas também importante norma social para o desenvolvimento humano aceita em todo o mundo (ROMEIRO, 2001). Partiu-se, também, do pressuposto de que conhecimentos e práticas já tinham sido aprendidos pelos sujeitos que compõem o APL, como foi indicado pela leitura do ambiente conjuntural e teórico em que se encontra o estado da arte sobre o objeto em análise.

\section{Arranjos Produtivos Locais}

Esta seção inicia-se com considerações acerca de aglomerações produtivas, suas vantagens e como surgem. Em seguida, apresenta-se um relato sobre as características do apoio público e da governança, que correspondem a elementos essenciais para a configuração do arranjo produtivo local, que são analisados em duas seções distintas.

A despeito das dificuldades enfrentadas pelos pequenos negócios, existe o reconhecimento de que o isolamento das micro e pequenas empresas (MPEs), bem mais do que o tamanho dessas, acentua suas limitações para o desenvolvimento de capacidade inovadora e sobrevivência (SANTANA; TEIXEIRA; SOUZA, 2012).

Marshall (1996) indica que há diversas causas que levam à localização de indústrias, mas no caso da Inglaterra, as principais foram as condições físicas, tais como a natureza do clima e do solo, a existência de minas e de pedreiras nas proximidades, ou ainda um fácil acesso por terra ou mar. Mas, segundo Porter (1998), as raízes de um cluster podem muitas vezes ser atribuídas a circunstâncias históricas.

A interação entre as várias empresas e instituições pode ocorrer sob diversas nomenclaturas: cluster, distrito industrial, ambiente inovador. No Brasil, por uma questão de adaptação, tal nomenclatura vem sendo denominada de Arranjo Produtivo Local (APL) (AMARAL FILHO; SCIPIÃO; RABELO, 2004).

No tocante a denominação de APL, Amaral Filho (2005), define como aglomerações geográficas ou redes de empresas especializadas, funcionando de maneira organizada, baseadas em interações e mecanismos de coordenação. É possível que, sem coordenação, não exista propriamente um arranjo produtivo, mas apenas uma aglomeração física de empresas mantendo encontros casuais. O autor salienta, ainda, que a força do arranjo produtivo está no fato de possibilitar a inibição de ações espontâneas e erráticas por parte dos agentes, diminuindo o papel do acaso na emergência dos resultados, além de possibilitar a geração de economias externas e de escala entre as empresas (AMARAL FILHO, 2005).

Conforme Teixeira e Ferraro (2009), as aglomerações, ao contarem com uma estrutura de governança e uma política de apoio, constituem-se como Arranjos Produtivos Locais ${ }^{1}$, esquematizados na Figura 1 abaixo:

Figura 1: Definição de APL

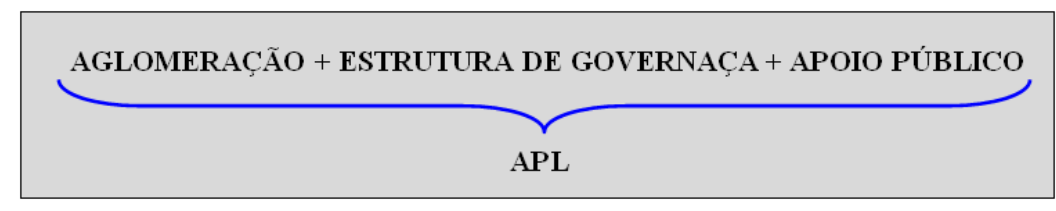

Fonte: Teixeira e Ferraro (2009, p.22)

Já Amaral Filho et al. (2002) indicam que a presença dos elementos: capital social, organização produtiva e articulação político institucional formam o que está sendo denominado de Arranjo Produtivo, "devendo ser específico para cada Núcleo Produtivo e evolucionário para todos os Núcleos" (AMARAL FILHO et al., 2002, p.03).

A denominação de Arranjo Produtivo Local, com os trabalhos da Redesist ${ }^{2}$, passou a ser associada ao conceito de Sistema Produtivo Local. Nesse sentido, Amaral Filho (2008, p.03) apresenta que Sistemas e Arranjos Produtivos Locais (SAPLs) podem ser entendidos como um conjunto de atores econômicos, políticos e sociais, localizados em um mesmo território, atuando tanto nos setores primário e secundário quanto no terciário, e que apresentam vínculos formais ou informais ao desempenharem atividades de produção e inovação.

Dos elementos-chaves que compõem a noção de Sistema e Arranjos Produtivos Locais, os principais são

\footnotetext{
${ }^{1}$ Optou-se por essa definição de arranjo produtivo local para a consecução da presente pesquisa. Nas próximas seções detalhase melhor o que pode ser entendido por apoio público e estrutura de governança.

${ }^{2}$ Uma rede de pesquisa interdisciplinar, formalizada desde 1997, sediada no Instituto de Economia da Universidade Federal do Rio de Janeiro e que conta com a participação de universidades e institutos de pesquisa no Brasil, América Latina, Europa e Ásia (REDESIST, 2014).
} 
"conjunto", "atores", "vínculos" e "território". Uma vez articulados estes elementos formam um sistema produtivo localizado, no qual o "Arranjo Produtivo" passa a ser seu regime de funcionamento. Em outras palavras, Arranjos Produtivos Locais (APLs) podem ser considerados como regimes e conformações de Sistemas Adaptativos Complexos, "nos quais os agentes se relacionam, aprendem, selecionam e evoluem". (AMARAL FILHO, 2008, p.5).

Cabe destacar que a noção de "local" não pode ser fechada ao ponto de limitar o aproveitamento da abordagem de SAPLs somente àquelas relações ocorridas dentro de uma fronteira delimitada, político administrativamente e ou definida pela ocorrência de uma aglomeração de empresas ou produtores. Compreende-se que a aplicação da abordagem de SAPLs abrange as relações que estão fora da aglomeração, territorialmente definida, desde que esteja dentro do conjunto de interações e conectividades estabelecidas pelos atores (AMARAL FILHO, 2008).

Por fim, cabe ressaltar, que se optou por utilizar o termo Arranjo Produtivo Local (APL), uma vez que a abordagem de SAPL está, na maioria das vezes restrita aos trabalhos da Redesist, assim como se entende que na denominação de Arranjo Produtivo Local (APL) está implícito o conceito de Sistemas Produtivos Locais (SPL).

A seguir, é examinado em como os Arranjos Produtivos Locais (APLs) podem ser apoiados por políticas públicas que visam ao desenvolvimento local.

\section{Apoio Público e APL}

A questão das políticas públicas de apoio aos APLs, que têm como base a aglomeração de MPEs, não é tarefa fácil, pois, conforme a teoria econômica "moderna", a intervenção do Estado na economia se justificaria por algumas razões, dentre elas: (i) quando há riscos contra a concorrência empresarial e o bem-estar do consumidor; (ii) quando as informações que circulam entre os agentes são assimétricas; (iii) quando as externalidades produzidas pelos agentes são negativas e (iv) quando há razão para a existências de monopólios naturais. Portanto, não há uma teoria econômica adequada e capaz de fornecer respaldo no caso dos APLs (AMARAL FILHO, 2008).

Associado a esse fato, há também a questão de que as políticas públicas de apoio aos APLs não podem simplesmente adotar experiências que se tornaram "consagradas", em determinadas regiões, para servir de espelho para as demais regiões e localidades, devido às diferenças apresentadas em nível das instituições e da cultura de cada região. Sem falar que os APLs oferecem uma demanda difusa por políticas. Ora o foco parece ser puramente setorial ora apela para uma abordagem territorial, assim como, muitas vezes, demandam por políticas sociais, com objetivos voltados para a equidade, enquanto outros reclamam por políticas de corte mercantil, que visam à concorrência, à competitividade e à eficiência das empresas (AMARAL FILHO, 2008).

Mesmo diante de todas essas dificuldades, o fato é que, conforme Cassiolato e Szapiro (2003), a partir do início dos anos 1990 a ideia de aglomerações tornou-se explicitamente associada ao conceito de competitividade, o que passou a interessar aos formuladores de políticas, fazendo com que distritos industriais, clusters, arranjos produtivos, passassem a ser tanto unidade de análise como objeto de ação de políticas industriais.

Esta estratégia, baseada no apoio às aglomerações produtivas especializadas, tem ganhado importância por parte das políticas públicas de geração de emprego e renda e de desenvolvimento regional e local (AMARAL FILHO; SCIPIÃO; RABELO, 2004).

Esses arranjos começaram a inspirar a construção de um modo diferente de desenvolvimento, um desenvolvimento endógeno, de baixo para cima, de dentro para fora e com certa autonomia, não absoluta, mas cuja força está nas vocações econômicas e identidades culturais locais, entre outros aspectos. Esses arranjos começaram a mostrar que é possível implementar estratégias e políticas produtivas de caráter inclusivo (AMARAL FILHO, 2005), assim como também podem apoiar desde a criação de infraestrutura até a especialização dos trabalhadores no contexto local ou regional, por intermédio de apoios à educação técnica específica (SANTANA;TEIXEIRA;SOUZA, 2012).

De fato, Porter (1998) considera que o governo e o setor privado, trabalhando conjuntamente, devem reforçar e construir existentes e emergentes clusters, em vez de tentar criá-los inteiramente novos. Uma vez que a maioria dos aglomerados é formada independentemente da ação governamental, por vezes, apesar disso, eles são criados quando existe uma base de vantagens locacionais. Por já existirem, essas aglomerações poupam o exercício voluntarista criacionista exercido pelo velho método de planejamento, imposto de cima para baixo, que sempre pretendeu substituir o método modesto de aprendizagem evolucionista. Na realidade, o fenômeno está ali, não é preciso inventá-lo, nem criá-lo, resta apoiá-lo adequadamente (AMARAL FILHO, 2005). Portanto, é nesse sentido que Aquino e Bresciani (2005) afirmam que a função do governo é compreender a formação do grupo local, com o objetivo de estimular suas atividades.

É por esse motivo que, políticas que se mostram descentralizadas, modestas e abertas à participação dos agentes implicados, têm apresentado melhor desempenho do que aquelas políticas de tipo voluntarista (AMARAL FILHO, 2008). 
A ideia força que move as ações de apoio aos APLs aponta para uma ruptura em relação às políticas setoriais voltadas para as grandes estruturas, mas também em relação a políticas assistencialistas de pura transferência de renda. O que é relevante e sedutor é o fato de que os arranjos produtivos locais são frutos do empreendedorismo local e territorial, ocorrem naturalmente, ou seja, eles aparecem e desaparecem independentemente das vontades individuais de pesquisadores e formuladores de políticas e ou do próprio poder público. Entretanto, "o que se sabe, com mais clareza, hoje, é que as políticas de apoio podem melhorar a trajetória e a competitividade dos APLs" (AMARAL FILHO, 2005, p. 02).

Os aglomerados de empresas não são formados nem influenciados apenas por empresas, mas também por instituições públicas e privadas que os apoiam. Como vêm mostrando as aglomerações industriais exitosas, as pequenas empresas não vivem isoladamente nem vivem sem as interações institucionais e organizacionais. $\mathrm{O}$ apoio de instituições como o SEBRAE, secretarias de governo, centros tecnológicos, universidades, associações de classe, associações comerciais, centros de treinamento e capacitação da mão de obra, que geralmente ocorre na forma de treinamento, crédito, consultoria técnica, apoio às participações em feiras e dotação de infraestrutura, são fundamentais para o desenvolvimento das empreses e do aglomerado formado por elas. Além disso, há que se ressaltar que também a articulação com o governo municipal e estadual é de grande importância para a alavancagem de aglomerados produtivos (AMARAL FILHO et al., 2002).

Mas, como bem lembra Porter (1998a), é preciso ficar atento, pois nem todos os clusters terão sucesso, é claro, mas as forças do mercado e não as decisões governamentais devem determinar os resultados. Portanto, para justificar esforços de desenvolvimento de aglomerado, algumas sementes de um cluster devem ter passado por um teste de mercado.

Entretanto, para se transformar efetiva e amplamente em um modo diferente de promover o desenvolvimento, é necessário que os poderes públicos, em todos os níveis, incorporem a estratégia de apoio aos arranjos produtivos locais no elenco de políticas públicas (AMARAL FILHO, 2005).

Min (2005) lembra que, no contexto do Semiárido, já há um conjunto de políticas orientadas para a criação e fortalecimento de arranjos produtivos locais, graças à ação de instituições como o SEBRAE, Banco do Nordeste, ADENE, CODEVASF e órgãos de desenvolvimento dos governos estaduais.

O Programa de Desenvolvimento Integrado e Sustentável do Semiárido (Conviver) também é um exemplo das ações realizadas pela Secretaria de Programas Regionais (SPR), do Ministério da Integração Nacional (MIN), com vistas à reversão do quadro de desigualdade e de exclusão das regiões brasileiras e de suas populações, mediante a diminuição da vulnerabilidade da região, aumentando sua autonomia por meio da inserção produtiva de seus habitantes de forma sustentada e articulada com ações de combate à pobreza, de promoção de segurança alimentar e de infraestrutura hídrica, por meio da organização social e do aproveitamento de seus potenciais endógenos.

Nesse intuito, a SPR vislumbra no Ceará como prioritária, a região do Médio e Baixo Jaguaribe (Ceará), pois se identifica, nesses espaços, um significativo potencial para a geração de empregos em Arranjos Produtivos Locais e setores de atividade econômica que representam o início de um processo mais amplo de desenvolvimento da região Semiárida do Nordeste. Nesta Região, observa-se como potencial de geração de emprego e renda, a curto prazo, as atividades: fruticultura, piscicultura, ovinocultura, turismo, mineral, extrativismo/reflorestamento e biodiesel (MIN, 2009). A 4. Estrutura de governança e APL

A coordenação é o estado por meio do qual se pode diluir as tensões e estabelecer padrões estáveis de governança dentro do funcionamento do arranjo. Sendo o APL um universo complexo e adaptativo, a coordenação institucional, apresentada sob as formas de "regras" e "normas", coloca-se como peça central na estrutura organizacional, atuando como elemento de unidade e estabilidade do sistema (OSTROM; COX, 2010).

Existem diferentes formas de governança e hierarquias nos sistemas e arranjos produtivos, representando formas diferenciadas de poder na tomada de decisão (centralizada e descentralizada; mais ou menos formalizada) (LASTRES; CASSIOLATO, 2003).

Para Cassiolato e Szapiro (2003), as empresas locais podem se organizar, do ponto de vista da governança, em forma de "redes" ou de "hierarquias".

Os aglomerados em forma de "rede" podem ser encontrados em dois tipos. No primeiro tipo, as MPEs locais surgem a partir da existência, na localidade, de instituições científico tecnológicas de excelência. Como exemplo, cita-se os aglomerados de pequenas empresas de base tecnológica, onde a especialização ocorre em áreas científicas e tecnológicas, como Biotecnologia, Tecnologias da informação e Comunicações, Materiais Avançados etc. Para este tipo de aglomerados, podem ser identificados vários programas de estímulo público, voltados ao 
surgimento de tais empresas, como por exemplo, os programas de incubadoras. Cabe ainda destacar que estes programas, embora importantes, são insuficientes para garantir o crescimento e a sustentabilidade das firmas e a constituição das interações entre elas. Neste caso, a governança local é realizada através de uma combinação de estímulos público-privados.

Figura demonstra os arranjos produtivos no semiárido.

\section{Estrutura de governança e APL}

A coordenação é o estado por meio do qual se pode diluir as tensões e estabelecer padrões estáveis de governança dentro do funcionamento do arranjo. Sendo o APL um universo complexo e adaptativo, a coordenação institucional, apresentada sob as formas de "regras" e "normas", coloca-se como peça central na estrutura organizacional, atuando como elemento de unidade e estabilidade do sistema (OSTROM; COX, 2010).

Existem diferentes formas de governança e hierarquias nos sistemas e arranjos produtivos, representando formas diferenciadas de poder na tomada de decisão (centralizada e descentralizada; mais ou menos formalizada) (LASTRES; CASSIOLATO, 2003).

Para Cassiolato e Szapiro (2003), as empresas locais podem se organizar, do ponto de vista da governança, em forma de "redes" ou de "hierarquias".

Os aglomerados em forma de "rede" podem ser encontrados em dois tipos. No primeiro tipo, as MPEs locais surgem a partir da existência, na localidade, de instituições científico tecnológicas de excelência. Como exemplo, cita-se os aglomerados de pequenas empresas de base tecnológica, onde a especialização ocorre em áreas científicas e tecnológicas, como Biotecnologia, Tecnologias da informação e Comunicações, Materiais Avançados etc. Para este tipo de aglomerados, podem ser identificados vários programas de estímulo público, voltados ao surgimento de tais empresas, como por exemplo, os programas de incubadoras. Cabe ainda destacar que estes programas, embora importantes, são insuficientes para garantir o crescimento e a sustentabilidade das firmas e a constituição das interações entre elas. Neste caso, a governança local é realizada através de uma combinação de estímulos público-privados.

Figura 2: Mapa de arranjos produtivos no semiárido brasileiro.

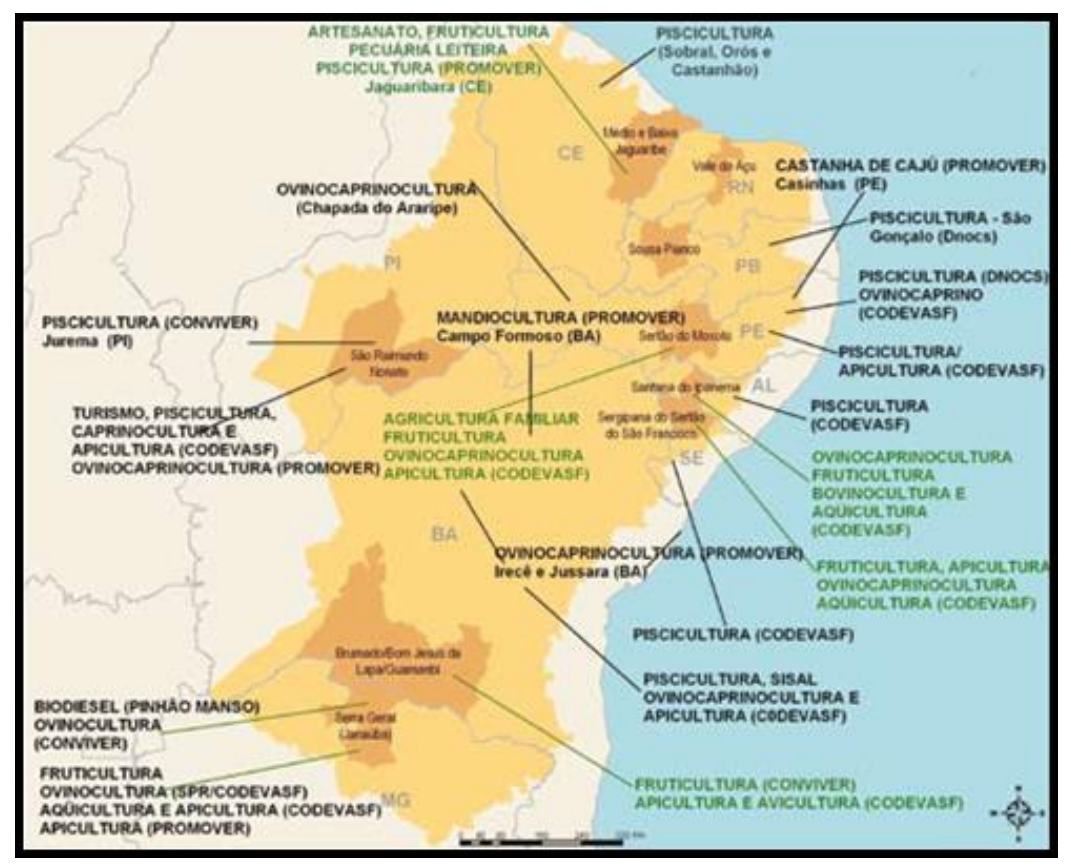

Fonte: Min (2009, p.43)

O segundo tipo de aglomerações de MPEs com governança em forma de rede pode ser caracterizado a partir dos chamados distritos industriais italianos, uma vez que correspondem à estrutura formada em torno de "setores", como calçados, vestuário, etc. onde a especialização é predominantemente setorial.

Quanto ao segundo tipo, no que se refere à governança do tipo "hierárquica", Cassiolato e Szapiro (2003) lembram da situação em que uma ou mais grandes empresas funcionam como "âncora" na economia regional, com fornecedores e provedores de atividades de serviços. 
Conforme destacam Pieranti, Rodrigues e Peci (2007), a governança assume uma importância cada vez maior e se refere às relações complexas entre o Estado, o setor privado e a sociedade civil organizada.

É um processo de coordenação de atores, de grupos sociais, de instituições de apoio, com vistas ao alcance de propósitos discutidos e definidos coletivamente. Para entender melhor como esta coordenação pode ocorrer, Silva, Castro e Antonialli (2014) desenvolveram a seguinte tipologia, como aparece no Quadro 1: Tipologia de governança produtiva.

Quadro 1: Tipologia de governança produtiva.

\begin{tabular}{|l|c|l|c|}
\hline \multicolumn{2}{|c|}{$\begin{array}{c}\text { Tipologia de governança em } \\
\text { aglomerações produtivas }\end{array}$} & \multicolumn{2}{c|}{$\begin{array}{c}\text { Grau de desenvolvimento/maturidade da } \\
\text { coordenação }\end{array}$} \\
\cline { 3 - 5 } $\begin{array}{c}\text { Intensidade da } \\
\text { interação produtiva entre } \\
\text { empresas, instituições de apoio } \\
\text { e poder público }\end{array}$ & Reduzida & $\begin{array}{c}\text { Governança } \\
\text { embrionária }\end{array}$ & $\begin{array}{c}\text { Governança } \\
\text { moderada }\end{array}$ \\
\cline { 3 - 5 } & Elevada & $\begin{array}{c}\text { Governança } \\
\text { frágil }\end{array}$ & $\begin{array}{c}\text { Governança } \\
\text { avançada }\end{array}$ \\
\hline
\end{tabular}

Fonte: Silva, Castro e Antonialli (2014, p. 10)

Com a correlação entre o grau de desenvolvimento e maturidade da coordenação com a intensidade da interação produtiva entre os agentes da aglomeração (especialmente as empresas, as instituições de apoio e o poder público), tem-se a classificação da governança em:

a) Governança embrionária - caracterizada por um reduzido grau de desenvolvimento da coordenação da aglomeração e reduzida interação entre os agentes. O papel que as instituições de apoio e o poder público desempenham é incipiente para promover uma coordenação organizada da aglomeração como um todo;

b) Governança frágil - tipo que se distingue pela elevada interação entre os agentes da aglomeração, porém, com reduzido grau de desenvolvimento da coordenação, pois as instituições de apoio e o poder público desempenham um papel ainda tímido nessa articulação;

c) Governança moderada - assinala um elevado grau de desenvolvimento e maturidade da coordenação, pois o poder público e as instituições de apoio desempenham um papel articulador e promotor da coordenação. Em contrapartida, a interação produtiva é reduzida entre os agentes;

d) Governança avançada - sinaliza para um grau elevado de desenvolvimento e de maturidade por parte da coordenação, da aglomeração e elevado grau de interação produtiva entre os agentes que a compõem. Nesse caso, as instituições de apoio e o poder público desempenham um papel efetivo nas ações e projetos da aglomeração, estimulando uma coordenação integrada, eficiente e competitiva.

Para melhor ilustrar tais tipologias, os autores ainda apresentam uma representação esquemática, disponibilizada na Figura reproduzida a seguir:

Figura3: Representação esquemática dos tipos de governança

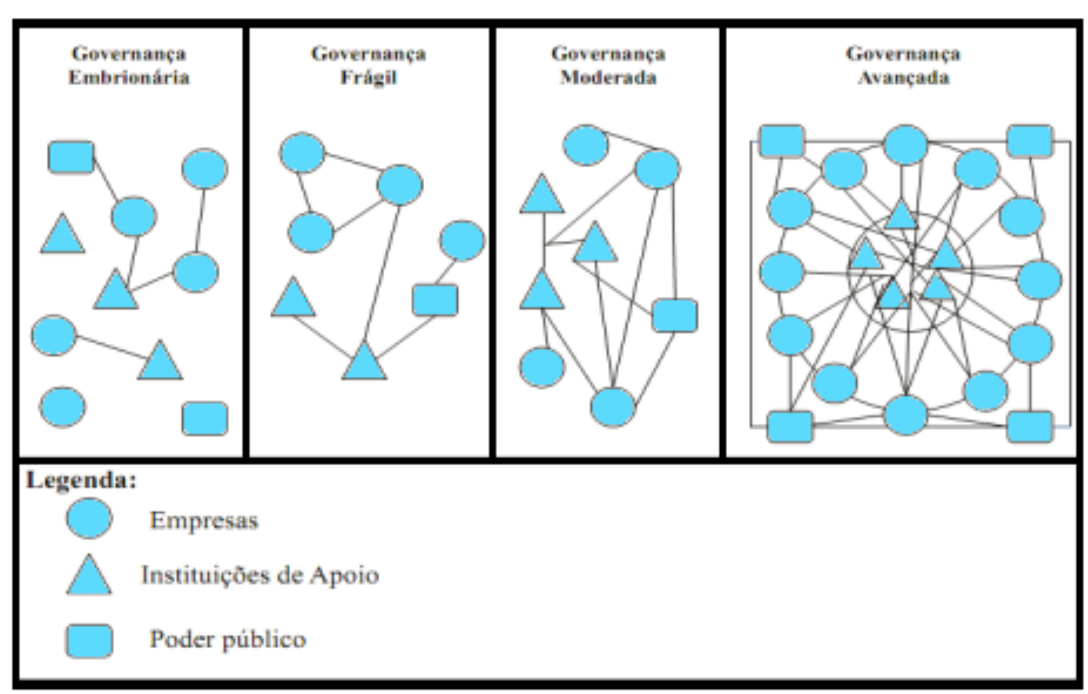

Fonte: Silva, Castro e Antonialli (2014, p. 11) 


\section{Método}

A abordagem metodológica adotada aponta para a pesquisa qualitativa. Flick (2004, p. 18) ressalta que a era das grandes narrativas e teorias chegou ao final: "as narrativas devem ser limitadas em termos locais, temporais e situacionais", o que obriga a utilização de estratégias indutivas, ao invés de partir de teorias para testá-las, embora a criação de conceitos sensibilizantes seja influenciada por um conhecimento teórico anterior.

O objeto da presente pesquisa é o APL que se constitui no lócus para o processo de aprendizagem de conhecimentos e práticas sobre sustentabilidade. Segundo Souza (2010), o APL é composto por empresas produtoras de tilápia, fornecedoras de gelo, alevinos, juvenis, ração, gelo e gaiola (ou seus insumos) e outros equipamentos; distribuidoras e comercializadoras; consumidoras; organizações governamentais e não governamentais, voltadas à formação e treinamento de recursos humanos, informação, pesquisa, desenvolvimento e engenharia, promoção e financiamento; cooperativas, associações e demais órgãos de representação.

Documentos mais atuais fornecidos pela Secretaria de Desenvolvimento Econômico, Turismo, Aquicultura e Pesca de Jaguaribara (SEDETA, 2013; SEDETA, 2015), apontam para o seguinte número de componentes do APL, assim distribuídos e elencados no Erro! Fonte de referência não encontrada. 2 a seguir.

Para atender aos objetivos da pesquisa, optou-se por narrar as histórias, centrado na coleta de experiências dos participantes. Optou-se por utilizar a análise de narrativas como abordagem de interpretação dos resultados, pois se entendeu ser esta uma perspectiva analítica que possibilitaria "olhar" as informações coletadas de forma holística, integrando os dados coletados e construídos nas várias fontes mencionadas (ZACCARELLI; GODOY, 2014).

Quadro 2: Componentes do APL da piscicultura do Castanhão.

\begin{tabular}{|l|c|}
\hline \multicolumn{1}{|c|}{ Componentes do APL } & Número \\
\hline Piscicultores Individuais & Desconhecido \\
\hline Associação e cooperativas que congregam piscicultores individuais & 09 \\
\hline Processadores de pescado & 02 \\
\hline Fornecedor de Ração & 07 \\
\hline Fornecedor de Alevino & 04 \\
\hline Fornecedor de Gelo & 02 \\
\hline Fornecedor de equipamentos & 03 \\
\hline Instituição de apoio & 14 \\
\hline
\end{tabular}

Fonte: Adaptado de SEDETA (2013) e SEDETA (2015).

Uma pesquisa pode conter estes vários níveis simultaneamente. Sendo assim, elegeu-se como forma de contação da história da aprendizagem de conhecimento e práticas sustentáveis no APL da piscicultura do Castanhão, os relatos interpretativos desenvolvidos pela pesquisadora, baseados em entrevistas, observação de trabalho de campo, assim como de análise de documentos, em que também se conta histórias de outras histórias (RIESSMAN, 2008 apud ZACCARELLI; GODOY, 2014 ).

O material básico sobre o qual o trabalho se apoiou é representado por uma série de entrevistas com os participantes do APL da piscicultura do Açude Castanhão, que inclui empreendedores do núcleo produtivo não oneroso, empresários do núcleo produtivo oneroso ${ }^{4}$, representantes de órgãos governamentais e não governamentais e agências de crédito que trabalharam na implantação e desenvolvimento do arranjo, assim como representantes de cooperativas e associações ligadas à piscicultura. Ressalte-se que se trata de uma escolha intencional e por acessibilidade, em que se buscou, a partir de levantamentos preliminares, conhecer aqueles atores que apresentam maior relevância para a consecução das atividades do APL. A identificação dessa relevância foi construída à medida em que as entrevistas se efetivaram. Para a realização das entrevistas, optou-se por 03 (três) roteiros semiestruturados como instrumento de coleta, sendo cada um deles direcionados aos seguimentos: produtor, cooperativas/associações e instituições de apoio.

Cabe ressaltar que foram 32 pessoas entrevistadas e realizadas 9horas, 49minutos e 55 segundos de entrevista. Este tempo foi distribuído entre 12 (doze) entrevistas individuais e 6 (seis) aplicada a um pequeno grupo de pessoas. A observação direta também foi utilizada como fonte de coleta, porque possibilita ver o que não é percebido rotineiramente, além de aclarar fatos que as pessoas não informariam voluntariamente, possibilitando ir além da percepção de outros, desenvolvendo-se uma visão mais compreensiva (PATTON, 2002).

Sobre a pesquisa documental, Godoy $(1995$, p. 21$)$ a define como sendo "o exame de materiais de natureza diversa, que ainda não receberam um tratamento analítico ou que podem ser reexaminados, buscando-se novas e ou

\footnotetext{
${ }^{3}$ Optou-se por não elencar o mercado consumidor.
} 
interpretações complementares". Os documentos analisados foram principalmente leis, mas também relatórios de atividade fornecidos pela Associação Cearense de Aquicultura (ACEAQ), SEDETA e Departamento Nacional de Obras Contra a Seca (DNOCS).

A estrutura narrativa eleita consiste inicialmente na descrição da história do desenvolvimento do APL da piscicultura do Castanhão e na fase de análise e discussão dos resultados propriamente dita, em que são identificados os elementos constitutivos do APL, conforme revisão da literatura apresentada.

\section{A História Do Processo De Aprendizagem De Conhecimentos E Práticas Sobre Sustentabilidade No APL Da Piscicultura Do Castanhão}

Para Jaguaribara a piscicultura era algo desconhecido até o surgimento do Açude Castanhão. A construção do açude, que culminou com a mudança de localização da cidade, em 2001, causou enorme transtorno. Apesar dos benéficos que foram apresentados no campo e na cidade no tocante a infraestrutura, com essa mudança, "a cidade de Jaguaribara foi bastante prejudicada, em sua estrutura social e econômica" (Associação 1). Além de terem que sofrer com o reassentamento involuntário e todas as mazelas históricas, culturais, sociais e emocionais advindas deste, o único conhecimento que as pessoas da região possuíam sobre atividades econômicas aquáticas era a pesca artesanal em águas rasas de rios, riachos e lagoas, só que agora teriam que praticá-la em águas represadas com até 60 metros de profundidade, em um lago artificial de $325 \mathrm{~km} 2$ (na cota 100 metros), que parecia mais um pequeno mar de água doce (MATIAS, 2010).

$\mathrm{Na}$ realocação das pessoas que foi prevista pelo DNOCS, (cujo cadastramento foi realizado pelo Instituto de Desenvolvimento Agrário do Estado do Ceará (IDACE), a serviço da Secretaria de Desenvolvimento Agrário (SEAGRI, atual SDA), aquelas que não tinham terras, antes da conclusão da obra do Castanhão, seriam encaminhadas para 17 reassentamentos margeando o açude. Já os fazendeiros, proprietários de terras, seriam indenizados e as pessoas que moravam na cidade receberiam uma casa, seguindo os parâmetros anteriores da antiga cidade (Institucional 2).

Para a construção do Castanhão e o reassentamento involuntário das pessoas do entorno (rural e urbana), constituiu-se um grupo multiparticipativo que envolvia todos os segmentos da cidade, inclusive o Movimento de Atingidos por Barragens (MAB), a igreja, os produtores rurais, os pescadores, os comerciantes, os moradores da cidade e do campo, as lavadeiras, DNOCS, Governo do Estado, Prefeitura Municipal de Jaguaribara etc.. Portanto, a sociedade civil já estava de certa forma acostumada a apresentar suas reivindicações e cobrar os resultados 4 (LIMA, 2007).

Com a mudança para a nova cidade e para os reassentamentos, muita coisa ainda precisava ser feita do ponto de vista econômico. Portanto, coube ao SEBRAE/CE a elaboração do Plano de Reestruturação Econômica, que foi posteriormente debatido com representantes de todos os segmentos da sociedade. O Plano delineava, no primeiro semestre de 2001, três linhas estratégicas de atuação: a piscicultura, a agricultura irrigada e o turismo (SOUSA, 2007).

Com isso, constituiu-se uma rede de instituições para apoiar e mobilizar a sociedade civil do Castanhão em torno de atividades produtivas que lhes possibilitassem melhores condições de vida.

Esse novo começo não foi fácil. Como essas atividades ainda levariam muito tempo para se desenvolver, inclusive a piscicultura, que exigia investimento significativo de capital, algo que os pescadores não possuíam, assim como não dispunham de crédito bancário, sem falar na demora do governo no repasse dos recursos para implantação das atividades produtivas (Institucional 5), a saída inicial foi buscar junto a outros órgãos ajuda para a aquisição de redes e canoas apropriadas para a pesca em lugares profundos. Entretanto, em pouco tempo o grupo logo percebeu que a atividade não lhe rendia o suficiente para o sustento de suas famílias.

Muitos consideram que a história da piscicultura do Castanhão começou com a montagem da estação de piscicultura do DNOCS no final de 2003, quando ainda faltava muito pouco para concluir a obra. Seu papel sempre foi de cuidar para a preservação da tilápia com sua característica genética original e, ainda, manter a diversidade de outras espécies de peixe, além de procurar garantir a reprodução em águas paradas. Como bem lembra um dos produtores: "o DNOCS foi o celeiro não só de trazer a tilápia, mas também de capacitação. A base do nosso conhecimento de tilápia foi o DNOCS" (Produtor 4).

\footnotetext{
${ }^{4}$ No trabalho de Araújo e Sena (2006) é destacada a emergência do Movimento dos Atingidos por Barragens (MAB) na região atingida pelo barramento e sua participação nas reivindicações para a população deslocada.
} 
O DNOCS também foi responsável pela definição da espécie de tilápia utilizada. Conforme os técnicos, a tilápia implantada é de qualidade genética superior e não geneticamente modificada, portanto, é também função da estação de piscicultura manter a "cepa" como veio da natureza, por meio de trabalho de preservação da espécie5. Para se ter uma ideia da superioridade dessa espécie, ressalte-se que " a tilápia cultivada antes da importação da Tailândia, durante seis meses de engorda, chegava no máximo a 350g. Com essa espécie, em quatro meses de engorda, chega a 800 g" (Institucional 3).

Outra vantagem deste peixe é que apresenta uma conversão alimentar altamente eficiente, pois produz $1 \mathrm{~kg}$ de peixe com aproximadamente $1,5 \mathrm{~kg}$ (pode chegar até $1,3 \mathrm{~kg}$ ) de ração. Portanto, apenas $0,5 \mathrm{~kg}$ vai para o meio ambiente. Esses valores de conversão são fundamentais não somente para a redução do custo de produção, mas também pela quantidade de material orgânico que resta e é jogado no ambiente, uma vez que será mais fácil para o ambiente (bactérias, algas e peixes livres) digerir estes refugos, já que são lançados uma quantidade menor.

Mas para a implantação da atividade, além da estação de piscicultura, foram necessários muitos outros cursos e para que para isso fosse possível, várias instituições como DNOCS, Governo do Estado, SEBRAE e, ainda, prefeitura de Jaguaribara, uniram forças para ensinar tudo que era preciso. "Foram necessárias parcerias entre várias instituições para dar treinamento e capacitação" (Associação 1).

Mas foi só com o sucesso da primeira despesca dos primeiros produtores no final de 2003, que os olhares se voltaram para a piscicultura. Com os resultados alcançados, a Associação dos Pescadores da Barragem Castanhão (ASPBC), que foi fundada para organizar estes poucos produtores, passou a ser demanda por novas iniciativas.

Além de merecer destaque o espírito empreendedor desse grupo inicial de 07 (sete) piscicultores, haja vista o desconhecimento e as incertezas que rondavam à época de implantação dessa iniciativa, é importante também ressaltar a forma de organização desse grupo inicial, também conhecido como Pioneiro, que pressupunha o compartilhamento de atividades em todas as áreas. Como por exemplo, para a produção, foi elaborada uma escala de trabalho em que a cada 24 horas uma dupla de pescadores assume a tarefa de realizar todo o manejo do empreendimento. Eles ficavam responsáveis pelos trabalhos de alimentação e vigilância em todo o projeto. Com isso, constituíam-se em produtores semiautonomos, ligados não somente pelas tarefas compartilhadas, mas também pelo tipo de aval que era exigido pelo banco para o financiamento.

Essa também foi a forma de estruturação e organização pensada para os 7 (sete) grupos formados com a chegada dos novos 58 sócios à ASPBC, que tinham sido também contemplados com financiamento do Banco do Nordeste, em julho de 2004.

Com a ampliação da ASPBC, a atividade da piscicultura cresceu bastante atraindo o pequeno produtor local, todos eles organizados no entorno de uma associação de produtores. Uma iniciativa mais ou menos semelhante à ASPBC ocorreu na península de Curupati em que com apoio direto do governo do estado, como fruto de contrapartida ainda pelo deslocamento compulsório da comunidade, foram investidos recursos a fundo pedido para implantação de uma cooperativa de produtores que funciona até hoje e que pressupõe não só o compartilhamento das tarefas entre os produtores, mas também os custos e sobras.

Outras iniciativas que merecem destaque são a Associação dos Criadores de Tilápia do Castanhão (ACRITICA), a Associação dos Aquicultores da Barragem Castanhão (AABC), Associação dos Piscicultores do Jaburu (APIJA), Associação dos Piscicultores do Mineiro (ASPM) e Associação dos Pescadores do Castanhão Novo (APAC).

Em 2005, foi a vez de começar a se pensar no beneficiamento da tilápia. Como a produção já tinha aumentado consideravelmente desde a criação do grupo Pioneiro, a cidade de Jaguaribara passou a despertar a atenção do Ministério da Integração Nacional, que encaminhou técnicos da Secretaria de Programas Regionais (SPR) para a implantação do Projeto Produzir, que, integrado à piscicultura existente, passou a fabricar bolinha de peixe, filé e hambúrguer de peixe (fishburger), artesanato entre outros derivados. Para melhor organizar a atividade, as pessoas que participaram desses cursos fundaram a Associação dos Produtores e Processadores de Peixes de Jaguaribara e Lages (APLAGES) formada por diversos grupos de produção conforme a especialidade de cada um.

Em 2006, começaram a ser implantados no Castanhão, os primeiros parques aquícolas do país - verdadeiras "fazendas" para a produção intensiva de pescado. Esta proposição de parques aquícolas está baseada na percepção do MPA (2014), de que esses espaços, além de se constituir em um meio para geração de emprego e renda por meio da piscicultura, também se constituem em excelente mecanismo para evitar impactos ambientais indesejados e garantir o uso múltiplo das águas.

\footnotetext{
${ }^{5}$ Outros tipos de tilápia são utilizados, mas a grande maioria tem sua origem nas unidades do DNOCS.
} 
Parque aquícola é um espaço físico contínuo em meio aquático, delimitado, que compreende um conjunto de áreas aquícolas afins, em cujos espaços físicos intermediários podem ser desenvolvidas outras atividades compatíveis com a prática da aquicultura (MPA, 2014)

O processo seletivo público, para a cessão das áreas aquícolas delimitadas nos parques, pode ser oneroso ou não oneroso. A seleção de áreas não onerosas tem forte cunho social e são ofertadas gratuitamente, mediante licitação não onerosa observando parâmetros socioeconômicos.

Já a seleção de empreendedores para as áreas onerosas é fruto de processos de licitação em que o vencedor é aquele disposto a pagar mais pelo uso da área. "Além de ser um negócio que pode ser lucrativo, os interessados em cultivar pescados nos parques aquícolas levam uma grande vantagem: as áreas são cedidas já com todos os seus aspectos legais e ambientais de cessão totalmente resolvidos" (MPA, 2014).

Foi por essa época que se intensificaram as promessas do governo (DIÁRIO DO NORDESTE, 2008) no tocante ao oferecimento de infraestrutura (estradas, energia elétrica, unidades de beneficiamento, pontos de apoio em terra etc) para o desenvolvimento da atividade. Essas promessas já tinham sido feitas outras vezes, mas nada tinha sido cumprido. "A atividade era desenvolvida assim mesmo, sem o apoio do governo, sem falar que muitos empresários já tinham até invadido o açude" (Associação 2).

A chegada desses grandes produtores por meio do processo de licitação (ou não) também foi importante para a aquisição de novos conhecimentos, pois por exigência de uma maior profissionalização do negócio, precisavam manter quadro de pessoal qualificado na fazenda, como engenheiros de pesca, veterinários e engenheiros agrônomos, que também contribuíram para a disseminação de conhecimentos sobre outras formas de manejo.

Os problemas ambientais também começaram a chamar mais atenção. Se antes as vísceras e o peixe morto eram lançados no açude ou em suas margens, com o aumento substancial da produção essa prática não conseguia mais passar despercebida, o que levava à necessidade de encaminhamento mais apropriado, embora a fiscalização pelos órgãos ambientais não fosse uma prática corriqueira (Associação 2). A poluição nos pontos de apoio em terra provocada, em grande parte, pelos dejetos humanos, sacos de ração e vísceras provenientes da evisceração nas margens do açude, foram formas de poluição que passaram também a chamar atenção, mas ainda sem uma solução definitiva, haja vista os empecilhos relacionados à complicação da logística em manter banheiros químicos às margens do açude e os custos e os riscos financeiros envolvidos na implantação de plantas de beneficiamento do pescado, bem como a dificuldade de conscientização das mentalidades em encaminharem adequadamente os sacos de ração em vez de queimá-los às margens do açude.

Com o aumento do consumo de ração no local, os produtores e associações não precisavam mais se deslocar para adquiri-las. Os próprios fornecedores passaram a visitar a cidade semanalmente para realizar suas vendas. As fábricas de ração que atuam no Castanhão têm vários engenheiros de pesca e agrônomos nas suas equipes de venda que prestam suporte aos clientes, repassando não somente técnicas de manejo mais eficientes, como também orientando quanto a importância de um ambiente sustentável para garantia da competitividade do negócio.

Outro parceiro que passou a atuar em Jaguaribara em 2009 foi a Piscis. A empresa é fruto de pesquisas realizadas por seu fundador, André de Freitas Siqueira, e apoiada por instituições de pesquisa e tecnologia como CNPQ, FINEP, IEL, INTECE e SEBRAE. A empresa realiza o processamento de resíduos provenientes da produção e beneficiamento da tilápia, coletando, transportando, extraindo óleo a partir das vísceras do peixe e aproveitando os efluentes e resíduos na produção de composto orgânico.

Outra parceira que também tem contribuído com os conhecimentos e práticas do setor da Piscicultura é a ACEAQ. A associação já existia há muito tempo, mas estava muito dispersa e em julho de 2010, como proposta de técnicos da SPA, as atividades foram renovadas e passaram desde aquela época a realizar reuniões periódicas.

Em 2012, a entidade passou por outra renovação quando a ADECE mobilizou a câmara setorial da tilápia, com o intuito de desenvolver ainda mais o setor e o presidente da ACEAQ, o produtor Camilo Diógenes, foi constituído presidente da CSTilápia, o que levou a ACEAQ a se constituir em um dos principais articuladores junto ao poder público. "A ACEAQ também tem a vantagem de trazer o setor público que está inserido no processo da cadeia produtiva. ACEAQ funciona como catalisador de benefícios e de trocas de informações com o setor público" (Produtor 5).

A ACEAQ está fomentando, desde meados de 2014, o licenciamento das áreas de apoio à produção no Castanhão. A associação articulou com SEMACE e SEBRAE, através do Programa SEBRAETEC, uma força tarefa para realizar esta tarefa. A meta é fazer até o final de 2015, 36 licenciamentos.

\section{Arranjo Produtivo Local Da Piscicultura Do Castanhão}


Na discussão sobre o tipo de rede em que transitam as práticas e os conhecimentos sobre sustentabilidade, é importante ressaltar que esta rede se constitui especificamente de uma APL. Portanto, também é apropriado analisar as características desse tipo específico de rede - APL.

A narrativa revelou que o surgimento do APL foi possível devido a circunstâncias históricas (PORTER, 1998), que resultou no oferecimento de condições físicas locais apropriadas (MARSHALL, 1996).

Como visto na narrativa, a interação entre as várias empresas e instituições contribuiu para ocorrer o APL da piscicultura do Castanhão.

A narrativa da história de aprendizagem de conhecimentos e práticas de sustentabilidade evidenciou a aglomeração de empresas/associações/cooperativas especializadas, funcionando de maneira organizada, baseadas em interações e mecanismos de coordenação, realizado principalmente por entes públicos como PMJ, DNOCS, SEBRAE e SEAGRI/SDA. Portanto, não se tratava somente de aglomeração física de empresas mantendo encontros casuais, mas também da ação de atores coordenados com algumas ações de governança e com a presença de apoio público. Conforme Teixeira e Ferraro (2009), as aglomerações, ao contarem com uma estrutura de governança e uma política pública de apoio, constituem-se como Arranjos Produtivos Locais, como se observou no lócus da pesquisa em análise

Como visto na revisão teórica, a estratégia baseada no apoio às aglomerações produtivas especializadas tem ganhado importância por parte das políticas públicas de geração de emprego e renda e de desenvolvimento regional e local (AMARAL FILHO; SCIPIÃO; RABELO, 2004) e foi nessa perspectiva que o APL da piscicultura foi utilizado: como estratégia e política produtiva de caráter inclusivo (AMARAL FILHO, 2005), tendo sido incluída até nos planos do MIN (2005).

Entretanto, no início da história, ainda não existiam as aglomerações. Foi papel do poder público estimular a criação do aglomerado, como foi retratado na história narrada. Mas sua criação só foi possível, pois existia uma base de vantagens locacionais, restando apenas apoiar o movimento adequadamente (AMARAL FILHO, 2005). Portanto, a função do governo foi compreender a formação do grupo local com o objetivo de estimular suas atividades (AQUINO; BRESCIANI, 2005). Por isso, a fase da apresentação das alternativas possíveis e a escolha pessoal de cada um para participar dos projetos de desenvolvimento econômico disponível, representou fator decisivo, unindo vocação com oportunidade.

Esse modo de atuar, de forma aberta, modesta e descentralizada, como foi a participação dos órgãos citados anteriormente, conforme Amaral Filho (2008), têm apresentado um melhor desempenho do que aquelas políticas de tipo voluntarista, de cima para baixo (AMARAL FILHO, 2008) e isso pode ser muito bem observado em função dos resultados positivos que tem sido oriundo do APL da piscicultura do Castanhão.

A narrativa também destacou que para a configuração do APL da piscicultura, o fato relevante e sedutor (AMARAL FILHO, 2005) para seu desenvolvimento foi fruto do empreendedorismo local que ocorreu naturalmente. Foi também visto, que esses aglomerados de empresas não são formados nem influenciados apenas por empresas, mas também por instituições públicas e privadas que os apoiam.

Portanto, é a partir dessa observação que é conveniente entrar na discussão sobre governança. Uma rede formada por um APL requer a coordenação entre os agentes e atividades realizadas e cabe a Governança determinar como serão esses diversos modos de coordenação, que vão da produção à distribuição de bens e serviços, assim como do processo de geração, disseminação e uso de conhecimentos e de inovações (LASTRES; CASSIOLATO, 2003). Sendo assim, a governança constitui-se em um processo de coordenação de atores, de grupos sociais, de instituições de apoio, com vista ao alcance de propósitos discutidos e definidos coletivamente (CASTRO; ANTONIALLI, 2014), portanto um elemento fundamental para o desenvolvimento dos APLs.

Segundo Lastres e Cassiolato (2003), existem diferentes formas de governança e hierarquias nos sistemas e arranjos produtivos, representando formas diferenciadas de poder na tomada de decisão (centralizada e descentralizada; mais ou menos formalizada). Eles ainda sugerem que as empresas locais podem se organizar, do ponto de vista da governança, em forma de "redes" ou de "hierarquias".

O APL da piscicultura do Castanhão apresenta um tipo de governança em rede que ocorre em torno de um setor específico, o que no caso estudado é a piscicultura.

Conforme destacam Pieranti, Rodrigues e Peci (2007), a governança assume uma importância cada vez maior e se refere às relações complexas entre o Estado, o setor privado e a sociedade civil organizada.

A consideração de Halme (2001) de que o processo de aprendizagem em rede é definido pelo relacionamento entre duas questões estruturais importantes, como liderança e seus membros, remete a questão da governança da rede. 
Segundo a tipologia de governança proposta por Silva, Castro e Antonialli (2014), é possível afirmar que se trata de um tipo de governança frágil, que se distingue pela elevada interação entre os agentes da aglomeração, porém, com reduzido grau de desenvolvimento da coordenação, pois as instituições de apoio e o poder público desempenham um papel ainda tímido nessa articulação. Entretanto, é possível ainda considerar que a governança do APL vem sofrendo modificações, principalmente com a instalação da ACEAQ e da CSTilápia, que vem fazendo com que a governança venha aos poucos evoluir para um tipo moderado.

\section{Considerações Finais}

As análises realizadas revelaram que o surgimento do APL foi possível devido a circunstâncias históricas que acabou por resultar no oferecimento de condições físicas locais apropriadas para realização das atividades.

A pesquisa ainda evidenciou a existência de aglomeração de empresas/associações/cooperativas especializadas, funcionando de maneira relativamente organizada, baseadas em interações e mecanismos de coordenação, realizado principalmente por entes públicos como PMJ, DNOCS, SEBRAE e SEAGRI/SDA. Portanto, não se tratava somente de aglomeração física de empresas mantendo encontros casuais, mas também da ação de atores coordenados com algumas ações de governança e com a presença de apoio público.

Entretanto, a estrutura de governança identificada aponta para um tipo frágil, que se distingue pela elevada interação entre os agentes da aglomeração, porém, com reduzido grau de desenvolvimento da coordenação, pois as instituições de apoio e o poder público desempenham um papel ainda tímido nessa articulação. Entretanto, é possível ainda considerar que a governança do APL vem sofrendo modificações, principalmente com a instalação da ACEAQ e da CSTilápia, que vem fazendo com que a governança venha aos poucos evoluir para um tipo moderado.

Quanto à metodologia eleita, a análise de narrativas, mostrou-se apropriada para descrever o processo de evolução do APL da piscicultura e esclarecer sobre seus elementos componentes e em grande medida apresentar as interações que possibilitaram a aprendizagem de conhecimentos e práticas sobre sustentabilidade.

\section{Referências}

AMARAL FILHO, J. et al. Núcleos e Arranjos Produtivos Locais: Casos do Ceará. In: Seminário Internacional Políticas para Sistemas Produtivos Locais de MPME, 2002, Mangaratiba. Anais ... Mangaratiba, 2002. Disponível em: $<$ http://www.ipece.ce.gov.br/publicacoes/artigos/ART_4.pdf $>$. Acesso em: 03 set. 2014.

AMARAL FILHO, J. Arranjo Produtivo Local: Moda ou Modo? O Povo, Fortaleza, 10 dez. 2005. Disponível em: $<$ http://www.ric.ufc.br/biblioteca/jair_l.pdf> . Acesso em: 03 set. 2014.

AMARAL FILHO, Jair do. Arranjo Produtivo Local: Moda ou Modo? O Povo, Fortaleza, 10 dez. 2005. Disponível em: $<$ http://www.ric.ufc.br/biblioteca/jair_l.pdf > . Acesso em: 03 set. 2014.

AMARAL FILHO, J.; SCIPIÃO, T..; RABELO, D. Identificação e mapeamento das aglomerações produtivas especializadas no Ceará - pistas para identificação de Arranjos Produtivos Locais (APLs). Texto para Discussão No14, IPECE, Fortaleza, Brasil, 2004. Disponível em: < http://www.ipece.ce.gov.br/publicacoes/textos_discussao/TD_14.pdf >. Acesso em: 03 set. 2014

AMARAL FILHO, J. Sistemas e Arranjos Produtivos Locais: fundamentos evolucionistas. In: VI Encontro Nacional da Enaber- Associação Brasileira de Estudos Regionais e Urbanos, 2008, Aracaju. Anais .... Aracaju, 2008. Disponível em: <http://www.ric.ufc.br/biblioteca/jair_b.pdf>. Acesso em: 03 set. 2014.

AQUINO, André Luiz de; BRESCIANI, Luis Paulo. Arranjos produtivos locais: uma abordagem conceitual. Organizações em Contexto, Ano 1, n. 2, dezembro de 2005. Disponível em: $<$ file://C:/Users/Adriana\%20Bastos/Downloads/Aquino_Bresciani_2005_Arranjos-Produtivos-Locais-um_22003.pdf>. Acesso em: 02 set. 2014.

CASSIOLATO, J. E.; SZAPIRO, M. Uma caracterização de arranjos produtivos locais de micro e pequenas 
empresas. In: LASTRES, Helena M.M. CASSIOLATO, José E.; MACIEL, Maria L (org). Pequena empresa: cooperação e desenvolvimento local. Rio de Janeiro: Relume Dumará, p. 35-50, 2003.

DIÁRIO DO NORDESTE. Lotes do Castanhão são entregues a piscicultores. Fortaleza, 2008. Disponível em: $<\mathrm{http}$ //diariodonordeste.verdesmares.com.br/cadernos/regional//otes-do-castanhao-sao-entregues-apiscicultores-1.125300>. Acesso em: 14 nov. 2014.

GODOY, A. S. Pesquisa qualitativa: tipos fundamentais, Revista de Administração de Empresas, São Paulo, v. 35, n. 3, p. 20-29, mai./jun. 1995.

HALME, M. Learning for sustainable development in tourism networks.Business Strategy and the Environment, v. 10, n. 2, p. 100-114, 2001.

LASTRES, H. M. M.; CASSIOLATO, J. E. Glossário de arranjos e sistemas produtivos e inovativos locais. Rio de Janeiro: IE, 2003.

LIMA, F. P. F. Castanhão: do sonho à realidade. Fortaleza: Expressão, 2007.

MARSHALL, A. Princípio de economia. São Paulo: Nova Cultural, 1996. Coleção Os Economistas.

MATIAS, J. F. N. Casos de sucesso da aquicultura no Brasil. Brasília: Publicações FAO, 2010.

MINISTÉRIO DA INTEGRAÇÃO NACIONAL (MI). Secretaria de Políticas de Desenvolvimento Regional. Plano estratégico de desenvolvimento sustentável do semiárido. Brasília: MI-SDR, 2005. Disponível em: http://www.mi.gov.br/c/document_library/get_file?uuid=347a66e5-2e91-49b7-9bd5-

5762d4ae3e02\&groupId=24915. Acesso em: 27 agos. 2014.

MINISTÉRIO DA INTEGRAÇÃO NACIONAL (MIN). Secretaria de Programas Regionais. Programa de desenvolvimento integrado e sustentável do semiárido - conviver. Brasília: MI-SPR, 2009. Disponível em: http://www.mi.gov.br/c/document_library/get_file?uuid=5106593d-2ac0-477e-a539-

632c1b5967e6\&groupId=10157 Acesso em: 27 agos. 2014.

MINISTÉRIO DA PESCA E AQUICULTURA (MPA). O que é um parque aquícola? Disponível em: $<$ http://www.mpa.gov.br/aquicultura/aguas-da-uniao/parques-aquicolas>. Acesso em: 24 nov. 2014.

OSTROM, E.; COX, M. Moving beyond panaceas: a multi-tiered diagnostic approach for social-ecological analysis. Environmental Conservation, v. 37, n. 04, p. 451-463, 2010.

PATTON, M. Q. Qualitative research and evaluation methods. 3th. ed. Thousand Oaks: Sage, 2002.

PECI, A.; PIERANTI, O. P.; RODRIGUES, S. Governança e New Public Management: convergências e contradições no contexto brasileiro. Organizações \& Sociedade, v. 15, n. 46, 2014.

PORTER, M. E. Clusters and the new economics of competition. Harvard Business Review, v. 76, n. 6, p. 7790, 1998.

ROMEIRO, A. R. Economia ou economia política da sustentabilidade? Texto Para Discussão. Ie/Unicamp, Campinas, n. 102, 2001. Disponível em <http://www.eco.unicamp.br/index.php/textos>. Acessado em: 17 abr. 2013.

SANTANA, M. B.; TEIXEIRA, F., SOUZA, R. K. S. Escolha de aglomerados por políticas estaduais de Arranjos Produtivos Locais (APLs): um estudo do PROGREDIR-BAHIA. In: ENCONTRO DE ADMINISTRAÇÃO PÚBLICA E GOVERNO, 2012, Salvador. Anais.... Disponível em: $<$ http://www.anpad.org.br/admin/pdf/2012_EnAPG411.pdf $>$. Acesso em: 02 set. 2014.

SECREATARIA DE DESENVOLVIMENTO ECONÔMICO, TURISMO, AQUICULTURA E PESCA (SEDETA). Levantamento de dados setor aquícola - Açude Castanhão. Jaguaribara: SEDETA, 2015. 
SECREATARIA DE DESENVOLVIMENTO ECONÔMICO, TURISMO, AQUICULTURA E PESCA (SEDETA). Potencialidades aquícolas do Açude Castanhão. Jaguaribara: SEDETA, 2013.

SILVA, I. C.; CASTRO, C. C.; ANTONIALLI, L. M. Governança nas aglomerações produtivas: proposição de um modelo teórico de análise da trajetória de formação e desenvolvimento da coordenação. Revista Brasileira de Gestão e Desenvolvimento Regional, v. 10, n. 1, 2014.

SOUSA, L. N. Piscicultura: uma revolução no Ceará. In: DUARTE, Renata B. de A (Org.). Histórias de sucesso: agronegócios: aquicultura e pesca. Brasília: SEBRAE, 2007.

SOUZA, M. A. A piscicultura em tanques-rede como vetor do desenvolvimento local sustentável? o caso do Açude Castanhão - CE. Brasília, 2010.178 p. Dissertação (Mestrado) - Centro de Desenvolvimento Sustentável. Universidade de Brasília, Brasília. 2010.

TEIXEIRA, F.; FERRARO, C. Aglomeraciones productivas locales en Brasil, formación de recursos humanos y resultados de la experiência CEPAL- SEBRAE. CEPAL Série Desarrollo Productivo, nº 186, Santiago de Chile, mar. 2009.

ZACCARELLI, L. M.; GODOY, A. S. "Deixa eu te contar uma coisa...": possibilidades do uso de narrativas e sua análise nas pesquisas em organizações. Revista Gestão Organizacional, v. 6, n. 3, 2014. 